\title{
Attempt is a crime: a Sociological study of Suicide attempters in R.L.Jalappa Hospital and Research Center, Tamaka, Kolar District Karnataka State
}

\author{
Dr. G. M. Nagaraja ${ }^{1}$, N S. Anil ${ }^{2}$, S. Ravishankar ${ }^{3}$. Dr. Muninarayana ${ }^{4}$. \\ Dr. Mohan Reddy. \\ ${ }^{1}$ Assistant Professor in Sociology, Department of Community Medicine, Sri Devrajurs Academy of \\ ${ }^{2}$ Higher Education and Research, comprising Sri Devrajurs medical college. \\ ${ }^{3}$ Associate Professor Department of Community Medicine, Sri Devrajurs medical college, SDUAHER. \\ Assistant professor in Bio- statics Department of Community Medicine, Sri Devrajurs medical \\ college, SDUAHER. \\ ${ }^{4}$ Professor \& HOD Department of Community Medicine, Sri Devrajurs medical college SDUAHER \\ ${ }^{5}$ Professor \&HOD of Psychiatry R.L.Jalappa Hospital and Research Center Kolar,
}

\begin{abstract}
Studies from south India have reported high rates of suicide. We aim to understand the Sociodemographic factors methods and reasons for suicidal attempts. 109 Patients with history of attempted suicides were admitted to R.L.Jalappa Hospital Kolar, a tertiary care center. Of these 65patients survived and various methods of committing suicide included poisoning 47 cases, hanging 9cases, and alcohol and tablets consumption 29 cases, overdose of sleeping pills 19 cases. 24 Students involved in the study attempted hanging, poisoning, slit throat. Methods: Structured Questioners was administered to the subjects relating to the factors responsible for attempted suicide and survived. Results: In this study a total of 109 patients are admitted survived 65, death 31, Discharge against medical advice or not affordable 16.Peak occurrence of suicidal attempts was found in the second and third decades (15-35years). Suicidal attempts among Hindu constituted about $81.65 \%$. Among females illiterates are $69.5 \%$. Agricultures $55.04 \%$, Housewifes are $14.67 \%$,students $22.01 \%$, Eighty two percent of the subject were rural background and $17.43 \%$ are nuclear families and no income group are 36.69\% attempters. Conclusion: Our study reveals that people perceived suicide as an option to overcome interpersonal, financial stress, family problems, love affair and fear of failure in the examinations. Suicide and attempt suicide are slowly occupying the higher position of a public health problem caused by multiple factors and the age group of $16-45$ years, male sex, low education level, low socioeconomic status, illness and family problems are more prone to attempt suicide. Among these most of them are preventable and controllable.
\end{abstract}

Key Words: Suicide, NCRB, Extramarital relationship, Alcohol, Pesticide consumption

\section{Introduction:}

Suicide among young people has emerged as a major public health and clinical issue in many low and middle income countries, Suicide is mass great retreat from life.[1] Section 306 of Indian penal code ,if any person commits suicide, whoever abets the commission of such suicide, shall be punished with imprisonment of either description for a term which may extend to ten years, and also be liable to fine The motives underlying suicidal acts are numerous and complex. The importance of social influences can easily be exaggerated and influences of group motives of suicide under various factors are physical pain including frustration of instinctive demands, social sufferings and fears doubts and dreads [2]. Sociologist Durkheim says that suicide is widely belief to be an individual act, but a function of the individual and the society. Durkheim argued that particular circumstances could lead to a person taking his or her life, but personal reason may not adequately explain suicide for anonymity and impersonality, making may people to become isolated from the family and friends, and this could lead to frustration and suicide [3].

The world's most ruthless killer and the greatest cause of suffering on earth is extreme poverty. Poverty as a variable adversely influencing on health poverty is a multidimensional phenomenon, encompassing inability to satisfy basic needs lack of control over resources, lack of education and poor health. Poverty can be intensely alienating and distressing and if particular concerns are the direct and indirect effects of poverty [1]. The development and maintenance of emotional, behavioral and psychiatric problems, in developing countries are quite different. The substances most commonly used are self-poisoning. Many studies have reported that low socio-economic status is associated with high prevalence of mood disorders and stress of poverty may be causally related to depression. People who attempt suicide belong more often to the social categories associated 
with social destabilization and poverty. An attempt commit suicide is a crime. The Indian penal code upholds the dignity of human life, because human life is as precious to the state as it is, to the holder and state cannot turn a blind eye to a person in attempting to kill himself [4]. India has a population size comparable to that of china, and also estimates suicide rates based on a sample of the population. In India, however, suicide is illegal so there is an even greater danger of under reporting. Although the police investigate all suspected suicide cases, before final verdict is passed the case is reviewed by 'Panchayatdars', who are prominent citizens in the locality and neighbors' of the deceased. Many deaths in the rural areas are not registered at all, partly because of an inefficient registration system and partly because families fear the social and legal consequences associated with suicides.

National Crime Record Bureau, 2012, the official agency responsible for suicide data collection in India, Karnataka, Kerala, Tamil Nadu a south India state has the highest suicide rate among Indian states. In 2010 Karnataka 21.5/1000, Tamil Nadu 24.5/1000, Kerala 24.6/1000 Sikkim 45.9/1000, Pondicherry 45.5/1000, Nagaland $0.5 / 1000$, the national average being $11.4 / 1000$ [5]

\section{Objectives:} survivors.

To study the socio-demographic factors, methods and reason for attempted suicides among the

\section{Methods:}

A retrospective Observational study from July 2011 to June 2012 of all admitted patients of deliberate self-harm at Intensive Care Unit of R.L.Jalappa Hospital and Research Center, Kolar was done to examine the socio-demographic profile and clinical outcome of suicidal behavior. Data were collected from 65 patients using structured questionnaire. A total of 109 patients admitted to the intensive care unit consented for the participation in the study. A total number of 44 attempters was excluded from the study either due to refuse to take part in the study or discharged against medical advice or they cannot bear the expense. Remaining 65 attempters gave their consent and constituted the study group. The data thus obtained and compiled and analyzed. The following findings on survived suicidal behavior and associated factors were observed [6].

Table-1: Age-wise distribution of Suicide attempters

\begin{tabular}{|c|c|c|c|}
\hline Total & No.Females & No.Males & Age in years \\
\hline 01 & 1 & 0 & $16-25$ \\
\hline 47 & 21 & 26 & $26-35$ \\
\hline 29 & 19 & 10 & $36-45$ \\
\hline 19 & 8 & 11 & $46-55$ \\
\hline 11 & 3 & 8 & $56-65$ \\
\hline 01 & 0 & 1 & 65 \\
\hline 01 & 0 & 1 & Total \\
\hline $\mathbf{1 0 9}$ & $\mathbf{4 8}$ & $\mathbf{6 1}$ & \\
\hline
\end{tabular}

\section{Numbers attemters}

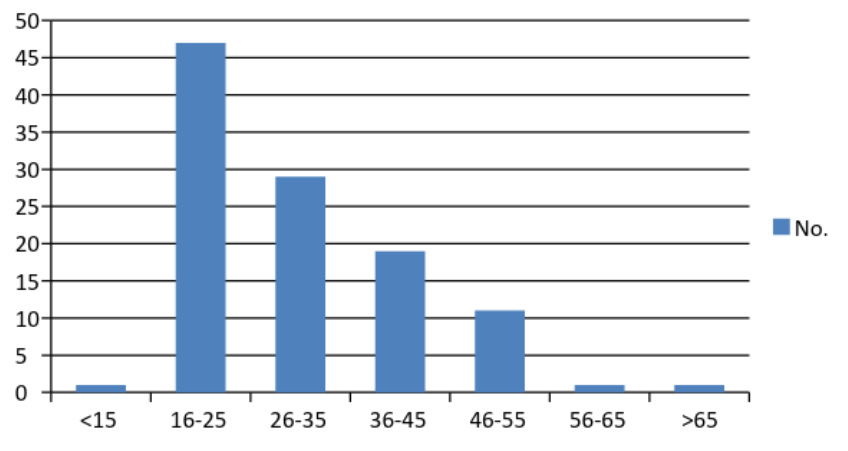




\section{Religion wise attemters}

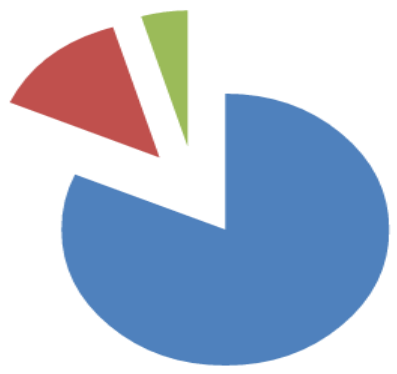

Muslim

Christian

Numbers Distribution

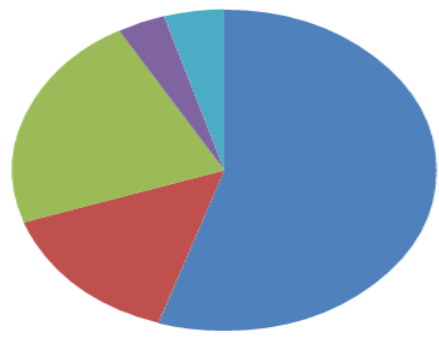

Agriculture Eousewife

Table 2 Socio-demographic factors of suicide attempters

\begin{tabular}{|c|c|c|c|c|c|}
\hline Percentage & Total & Female & Male & Sex & \\
\hline $81.65 \%$ & 89 & 37 & 52 & Hindu & Religion \\
\hline $13.76 \%$ & 15 & 9 & 6 & Muslim & \\
\hline $4.58 \%$ & 5 & 2 & 3 & Christian & \\
\hline $60.30 \%$ & 69 & 48 & 21 & Illiterate & Education \\
\hline $7.33 \%$ & 8 & 5 & 3 & Upto 5th & \\
\hline $11.92 \%$ & 13 & 7 & 6 & 5 th -10 th & \\
\hline \multirow[t]{18}{*}{$17.43 \%$} & 19 & 9 & 10 & Degree & \\
\hline & & $\%$ & Total & Per day & Income \\
\hline & & 45.87 & 50 & Rs $100-200$ & \\
\hline & & 9.01 & 10 & $201-300$ & \\
\hline & & 4.58 & 5 & $301-400$ & \\
\hline & & 0.91 & 1 & $401-500$ & \\
\hline & & 2.75 & 3 & 501-> & \\
\hline & & 36.69 & 40 & No income & \\
\hline & & $55.04 \%$ & 60 & Agriculture & Occupation \\
\hline & & $14.67 \%$ & 16 & Housewife & \\
\hline & & $22.01 \%$ & 24 & Student & \\
\hline & & $3.66 \%$ & 4 & Business & \\
\hline & & $4.58 \%$ & 5 & Employed & \\
\hline & & $17.43 \%$ & 59 & Nuclear & Type of family \\
\hline & & $36.69 \%$ & 35 & Joint & \\
\hline & & $9.17 \%$ & 15 & Extended & \\
\hline & & $82.56 \%$ & 90 & Rural & Domicile \\
\hline & & $17.43 \%$ & 19 & Urban & \\
\hline
\end{tabular}

Table 3 Percentage share of the methods adopted in committing suicide during 2010-2011

\begin{tabular}{|c|c|c|}
\hline$\%$ & No & Methods \\
\hline 43.11 & 47 & Poising \\
\hline 26.60 & 29 & Alcohol/ And tablets \\
\hline 04.50 & 05 & Drowning \\
\hline 08.25 & 09 & Hanging \\
\hline 17.43 & 19 & Overdose of sleeping pills \\
\hline $\mathbf{1 0 0 . 0 0}$ & $\mathbf{1 0 9}$ & Total \\
\hline
\end{tabular}




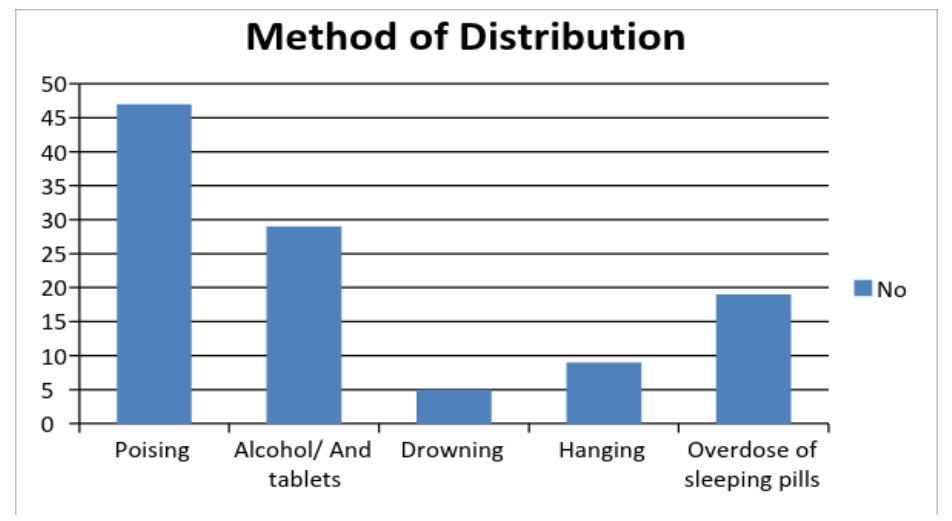

Survived suicide attempters -65

\begin{tabular}{|c|c|c|}
\hline \% & No & Sex \\
\hline 41.53 & 27 & Male \\
\hline 21.53 & 14 & Female \\
\hline 36.92 & 24 & Student \\
\hline $\mathbf{1 0 0 . 0 0}$ & $\mathbf{6 5}$ & Total \\
\hline
\end{tabular}

\section{Results:}

Of the 109 suicidal attempters studied 61(55.96\%) were males and $48(44.03 \%)$ females which gave male to female ration of 1.6:1. The age of 16-25 years male attempters was $27(24.27 \%)$ female 14 (12.84\%) higher than that of females. The youngest attempters were of $15 y e a r s$ age and the oldest were of 66years. Peak occurrence of suicidal attempts was found in the second and third decades (16-35years) and it was least in the sixth decade.

\section{Discussion}

Hindus constituted $81.65 \%$, Muslims $13.76 \%$, Christian $4.58 \%$ in our study. This may be due to the large Hindu population residing in rural area. Almost $(60.30 \%)$ of the subjects had not received any education. Almost half of study group $(36.69 \%)$ of suicidal attempters had education from matriculation up to college. Among suicide attempters $82.56 \%$ resided in rural India, $17.43 \%$ in urban as per our study. Most of the 65 suicidal attempters were from the lower (classes IV and V) socio economic groups. The number of suicidal attempters increased gradually with decrease in socio economic status. The total sample comprised about $55.04 \%$ of agriculturist, housewives $14.67 \%$, more number of males than females attempted suicide, $22.01 \%$ of student's are suicide attempters. According to our study 65 patient are survived from suicide [7].

Separate interviews with some of the ICU patients suggested physical and mental humiliation and torture by alcoholic husbands or in laws that prompted them to attempt suicide. Social support for women in general is inadequate, especially in rural areas. We believe that these factors have a strong role in enhancing vulnerability to suicide attempt among married woman [8]. The number of men attempting suicide also peaked during (May, July, august) this period though women out numbered this seasonal trend for attempter's points towards ecological factors. Agricultural work, increases during this period. The easy availability of pesticides, other studies of rural communities have reported similar findings [6]. Ignorance and carelessness about safe storage allows easy access to these lethal poisons in the household, marital disharmony, family conflict, conflict with newly married spouse was the commonest cause in both sexes followed by quarrel with in-laws[9], guardians, husbands, alcohol abuse, extra marital affair, dowry harassment, failed love affairs accounted for a small and comparable proportion[10]. Our studies have shown that economic hardship is a significant hardship, India being a developing country and there being an association between depression and lower socioeconomic status, the prevalence of depression is seen across the life span [11]. It could also be explained by cultural differences. The joint family system was in vogue till recently. This provided social security to younger individuals. The breakdown of the joint family and the emergence of the nuclear family could explain the occurrence of depression at younger ages due to reduced family support. It could be the problem of an unmarried girl being pregnant, pressure of independent living, abortion, infertility, wanting male child, discharge against medical advice and referral to a higher center quality of care or cost of medical expense [12]. 


\section{Verbatim accounts from interviewed group about the perception and causes of Suicide survivors}

\begin{tabular}{|l|l|}
\hline 2 & Women want divorce she is not getting so she attempt suicide. \\
\hline 1 & Finance or Chit fund cheated by chit fund agent. \\
\hline 14 & Loss of golden ornaments in the marriage function. \\
\hline 5 & $\begin{array}{l}\text { Failed in the 8th standard, Mother Scolded, Ill treatment by the Teacher, teased, } \\
\text { Pushups, he/she taken poison, tablets, English Language problem in the school /fail. }\end{array}$ \\
\hline 6 & His wife had affair with a boy/man, sexual inadequacy. \\
\hline 3 & Husband had extra marital relationship with unknown woman. \\
\hline 9 & Parents are not accepting inter-caste/religion marriage. \\
\hline 4 & $\begin{array}{l}\text { Every day working in the field it is difficult, because of irregularity of menstrual cycle } \\
\text { (7-12days) severe back pain, tiredness. }\end{array}$ \\
\hline 5 & $\begin{array}{l}\text { Step mother's children not sending school, not giving adequate attention to child's } \\
\text { health }\end{array}$ \\
\hline 5 & $\begin{array}{l}\text { Second wife, first wife harassing, blackmail and whole property in the hands of first } \\
\text { wife not sending her children To school, health, ornaments cloths. }\end{array}$ \\
\hline 6 & $\begin{array}{l}\text { illiterate Mother- in- law expect obedience, discipline, not waste food, ill-treatment, } \\
\text { teasing of my personality, over talking with neighbors, no freedom }\end{array}$ \\
\hline 2 & $\begin{array}{l}\text { Crossed 30years she need more sexual satisfaction, concern for her children's future, } \\
\text { her husband is not co-operating, she had illegal sexual relation with college student } \\
\text { caught by neighbors and wanted to commit suicide. }\end{array}$ \\
\hline 4 & $\begin{array}{l}\text { More bad dreams in the night, fear, thinking about children's marriage, dowry problem, } \\
\text { sleeplessness, I met Talisman, Worshiping god increasing heart beats in the night. }\end{array}$ \\
\hline 2 & $\begin{array}{l}\text { Land property is not distributed by his elder brother. } \\
\text { Orphans/mother married to unknown person. }\end{array}$ \\
\hline 2 & Because of T.B/HIV illness. \\
\hline & \\
\hline 1 &
\end{tabular}

Some of the suicide attempters are not express the reasons because of families fear and the social, legal consequences associated with suicide [6]. Cultural attitudes towards the women role in marriage may also partially explain the comparatively higher ratio of female to male suicide found in India as compared to developed countries where arranged marriages are common. The social and familial pressure on women to stay married even in abusive relationships appears to be one of the factors that increase the risk of suicide in women. When dowry expectations are not met, young brides can be harassed to the point where they are driven to suicide [13].

Psycho-social problems and stresses, such as conflict with parents, breakup of a relationship, school difficulties or failure of examinations, social isolation, and physical ailments commonly are observed in young people who attempt suicide [10]. National Crime Record Bureau report suggests that family problems are the major reason for suicide among 15-55age groups in our society. While mental illness attributed to 8.5\%, of cases; reasons are recorded as unknown in survived suicide cases. Adversities Including Physical violence, Emotional and sexual abuse can lead to substantially higher risk for suicide $[14,15]$. We suggested that many people going through difficult personal and financial circumstances view suicide as an option .suicide is not actively supported by society as suicide in a family is stigmatizing. The many suicides by farmers in different parts of India support this contention. People perceive poverty, lack of empowerment, a materialistic society and inefficient social and economic support system as a major factors that push individuals towards taking their own lives. Understanding the sociocultural and economic issues that modulate and increase the incidence of suicide deserve serious consideration. Suicide as an option among people with mental illness was also mentioned. Marital and family discord, and psychosocial stress were considered major contributors. The prevention and, early detection, treatment and rehabilitation of people with mental illness and emotional distress should be a priority. However, depression is also closely linked to psychosocial issues such as gender, poverty and unemployment, trying it to the socioeconomic environment. Although Suicide considered secondary mental illness in the west the results of our studies from the region suggest that interpersonal, familial and social factors rather than biological disease are the major contributors to suicide. There is a need to conduct similar studies in different populations and settings, and develop appropriate programmes to prevent suicide.

We asked question to suicidal survivors whether seriously conceded ending one's life, made a plan about ending one's life 8days to 15days before discharge from our R.L.Jalappa Hospital and Research Center. The outcome was report of suicidal attempters during one year. The reality of women's lives remains invisible to men and women alike and this invisibility persists at all levels beginning with the family to the nation. Although geographically men and women share the same space, they live in different worlds. The mere fact that, women hold up half the sky, does not appear to give them a position of dignity and equality true, that over 
the years women have made great strides in many areas with notable progress in reducing some gender gaps which we live is characterized by deeply unequal sharing of the burden of adversities between women and men. Sprawling inequalities persists in their access to education, health care, physical and financial resources and opportunities in the political, economic, social and cultural spheres [9].Women do more hours of work both in the family as well as in the agricultural field 16 .

\section{Conclusion:}

Social inequality and poverty have demonstrable adverse effects on health, a social and public health response to suicide is crucial in India, social and public health approach acknowledges that suicide is preventable. The study reveals that life is meaningful and sacred and does not possess its right in itself, but only in God also means dignity is upheld by his freedom which must be used with a sense of responsibility and faith in God. Suicide is a multifaceted problem and hence suicide prevention programmes should also be multidimensional, collaboration, coordination ,cooperation and commitment are need to develop and implement a national plan, which is cost effective, appropriate and relevant to the needs of the community.in India, suicide prevention is more of a social and public health objective than a traditional exercise in the mental health sector the time is ripe for mental health professionals to adopt proactive and leadership roles in suicide prevention and save the lives of thousands of young Indians. Suicide must be stopped. Professionals have a vital role to play. Survivors of a suicide experience severe bereavement and the family physician is identified as the key individual to initiate and ensure follow up care for the bereaved .In our study, the participants reported that the social impact was greater in rural communities. This may be because of the joint family system and close social bonding common in many places in India. Participants also identified sadness, depression, guilt and suicidal ideation as the major psychological reactions in families of victims. The financial impact of suicide was also recognized and was said to be profound in poor families, especially where the victim was breadwinner of the family. Participants also identified social costs including loss of respect in society, exclusion from village functions and spread of rumours about the cause and issues. These findings suggest that the community health team has a major role to play in providing support and counselling to the bereaved family.

Attempted suicides are slowly but steadily assuming the levels of public health problem and multiple factors responsible for attempted suicide were in the age group of 16-55 years male sex, low education level, socio-economic status, illness and family problems. The main limitation of this study is that it is social problems cannot be solved by applying technological solutions. As long as medicine depends on science and science promises hope, these is always hope for mankind and people who make decision should make them judiciously.

\section{Acknowledgment:}

We would like to express our appreciation to all the participants in the study who answered our questions and spent time with us discussing their experience sand making the study possible.

\section{Reference:}

[1]. Vijay Murali and Femi Oyebode, Poverty, Social Inequality and Mental Health. Advances in Psychiatric Treatment 2004; 10:21624.

[2]. Soman CR, Safarai S, Ramankutty V, Vijaykumar K and Ajayan K. Suicide in South India: A community based study in Kerala. Indian journal of Psychiatry 2009; 51(4): 261-4.

[3]. Ogar JN, Agba AM, Ogaboh. Suicide its moral, legal and sociological analysis. Journal of Arts Science \& Commerce International Referred Research Journal 2011; 11(1): 94-102.

[4]. Yadawad BS, Hareesh Gowda. Is attempted suicide is an offence? Journal of A.F.M 2005; 27(2): 108-11.

[5]. Monoranjitham, HelenChaeles, Saravanan, Jayakaran R, Abraham S, Jacob KS. Perceptions about suicide: A Qualitative study from southern India. The National Medical Journal of India 2007; 20(4): 176-9.

[6]. Eddletion. Patterns and problems of deliberate self-poisoning in the developing World O Journal of Medicine 2000; 93:715-31.

[7]. Hegde RS. Suicide in Rural Community. Indian Journal of Psychiatry 1980; 22: 368-70.

[8]. Gururaj G, Issac G, Issack MK, Subbakrishna DK, Ranjani R. Risk factors for completed suicide: A case control study from Bangalore, India. International Journal of Injury Control and Safety Promotion 2004; 11: 183-91.

[9]. Stark CR, Riordan V, Coonor RO. A conceptual model of Suicide in rural areas. The International Electronic journal of Rural and Remote health research, Education practice and policy 2011; 11, 1-11

[10]. American academy of pediatrics, Committee on adolescence, Suicide and suicide attempts in adolescence. Pediatrics 2000; 105(4): $871-4$.

[11]. Aravind Pillai, Tedy Andres, Vikram Patel, Violence, Psychological distress and the risk of suicidal behavior in young people. International Journal of Epidemiology 2009; 38: 459-69.

[12]. Chowdery AN, Banergee A Brahma, Das S, Sarker P, Biswas MK, Sanyal D, Hazra A. Preseptive study of suicidal behavior in Sundarban delta, West Bengal, India. The National Medical Journal of India 2005; 23(4): 201-05.

[13]. Dinesh Bhugra, Manisha Desai. Attempted suicide in South Asian Women, Journal of Advances in Psychiatric Treatment 2002; 8: 418-23.

[14]. Subramani Poongothi, Rajendra Pradeepa, Anbhazagan Ganesan, Viswanathan Mohan. Prevelence of Depression in a Large Urban South Indian Population. The Chennai Urban Rural Epidemiology Study 2009; 4(9): 1-14.

[15]. National Crime Record Bureau2012

[16]. Simone Goosen,Anton E Kunst Karien Stronkes,Irene EA vanOostrum,Daan GUitenbroek,Ad JFMKerkhol.Suicide death and hospital treated suicidal behavior in asylum seekers in the Netherlands:A national registry-based studyBMC Public Health 2011,11:484. 